\title{
PEDRA DE TROPEÇO: A IGUALDADE COMO PONTO DE PARTIDA
}

\author{
Lílian Do VALLE*
}

\begin{abstract}
A igualdade é fundamental e ausente, ela é atual e intempestiva, sempre dependendo da iniciativa de indivíduos e grupos que, contra o curso natural das coisas, assumem o risco de verificá-la.
\end{abstract}

\begin{abstract}
RESUMO: Onde fixar, em terras brasileiras, a atualidade e a importância da aventura de $O$ mestre ignorante? No ponto de partida, Jacotot havia colocado a igualdade, feita pedra de tropeço que descreve o estilo de diferentes trajetórias que o texto acaba por suscitar. No seio da "sociedade pedagogizada", a história da educação pública não pode ser dissociada do percurso totalmente excêntrico que veio descrevendo a exigência da igualdade política dos cidadãos. Sob as bases da desigualdade, nossas experiências educacionais vêm sendo construídas e, com elas, nossos ideais, nossas expectativas, nossas concepções acerca do ensinar, do aprender, do mestre, do aluno, do saber... Pedra de tropeço, a injunção à igualdade nos devolve às nossas práticas e instituições, a nossos modos de ser professor e de alimentar a ficção desigualitária. E se partir da igualdade significasse para o professor, por uma vez, partir... de sua própria realidade?
\end{abstract}

Palavras-chave: Emancipação. Igualdade. Sociedade pedagogizada. Escola pública. Professor.

\section{THe STONE OF STUMBLING: EQUALITY AS A STARTING POINT}

ABSTRACT: Where should we locate the actuality and importance of the adventure of The ignorant schoolmaster in the Brazilian experience? As a point of departure, Jacotot has established equality - a stumbling block that determines different reactions. Within the "pedagogized society", the history of public school cannot be dis-

Professora Titular de Filosofia da Educação da Universidade do Estado do Rio de Janeiro (UERJ).E-mail: lvalle@infolink.com.br 
sociated from the eccentric path described by the demand for political equality of its citizens. Our educational experiences have been constructed on the basis of inequality and, together with them, our ideals, our expectations, our conceptions of teaching, learning, teacher, student, knowledge. As a stumbling stone, the injunction to produce equality returns us to our usual institutional practices, our received ways of being teachers, all of which merely feed our non-egalitarian fiction. But what if starting from equality meant for the teacher, for once, starting from... his own reality?

Key words: Emancipation. Equality. Pedagogized society. Public school. Teacher.

$\mathrm{O}$ nde fixar, em terras brasileiras, a atualidade e a importância da aventura de Joseph Jacotot? No prefácio brasileiro para $O$ mestre ignorante, Jacques Rancière nos previne:

(...) trata-se, aqui, de uma voz solitária que, em um momento vital da constituição dos ideais, das práticas e das instituições que ainda governam nosso presente, ergueu-se como uma dissonância inaudita - como uma dessas dissonâncias a partir das quais não se pode mais construir qualquer harmonia da instituição pedagógica e que, portanto, é preciso esquecer, para poder continuar a edificar escolas, programas e pedagogias; mas, também, como uma dessas dissonâncias que, em certos momentos, talvez seja preciso escutar ain$\mathrm{da}$, para que $\mathrm{o}$ ato de ensinar não perca jamais inteiramente a consciência dos paradoxos que lhe fornecem sentido. (Rancière, 2002, p. 9)

Por pouco que se tenha feito da educação uma paixão durável, é impossível não reconhecer, com Rancière, a estranha fecundidade dos paradoxos que envolvem o ato de ensinar; mas como não reconhecer, igualmente, que a história dos ideais, das práticas e das instituições educacionais que ajudamos diariamente a instituir não apenas foi marcada, mas continuamente se mantém ao preço de nossa escrupulosa denegação desses mesmos paradoxos?

Mais difícil é admitir, no entanto, que o que faz calar os paradoxos são justamente as respostas mais apaixonadas que para eles fornecemos. É, no mínimo, assustador considerar que seja exatamente dos momentos de maior entusiasmo, de nossas convicções mais fecundas, de nossos consensos mais arduamente trabalhados que se alimentem as armadilhas em que o sentido de educar se esvai. Seria esse o ponto de partida para uma espécie de anarquismo, em tudo e por tudo antieducacional? Seria o caso de postular que, não sendo nenhuma resposta suficiente e definitiva, nenhum consenso confiável, nenhum entusiasmo promissor, 
deveríamos, de uma vez por todas, abdicar das respostas, dos consensos, de nosso entusiasmo: em uma palavra, da própria busca do sentido de ensinar?

Confesso que, apesar da irresistível atração que sobre mim exerceu, desde o primeiro momento, o texto de Rancière - ou, talvez, exatamente por isso - em minhas primeiras leituras foi quase inescapável o sentimento de que permaneceria entre nós o travo de uma dupla e peremptória desilusão, a se apelarem: no texto, sob a forma de um amargo ceticismo em face de qualquer construção comum; em mim, sob o modo do medo da desesperança, ou - devo dizer? - sob o modo do fascínio contraditório e profundo que o simples abandono adquire, em face de todos os desenganos que pontuam a defesa da coisa pública.

Desde seu lançamento, porém, o texto fez seu caminho, reproduzindo em pequena escala o antigo sortilégio que Jacotot, antes de Rancière, conhecera: uma história de condenações antecipadas e de arrebatamentos não menos precoces, mas nem por isso menos "razoáveis". Mais, talvez, do que ontem, estamos propensos a desconfiar das razōes que edificaram o mito da instrução pública, da sociedade do bom governo, do saber taumaturgo: não dedicamos a isso a maior parte de nossas reflexôes, ao longo das últimas décadas? Ocorre-me, porém, que essas são ainda as razões dos outros, tão afastados de nós pelo tempo quanto pela sábia distância, toda imaginária, que acreditamos estabelecer em relação a eles. O que dizer de nossas razóes? No meio tempo, o convite-desafio para elaborar um artigo é motivo de uma nova leitura, e eu finalmente descubro: nunca se esgotam, de fato, os desafios da tradução.

No ponto de partida, pois, a igualdade, feita pedra de tropeço que descreve o estilo de diferentes trajetórias que o texto acaba por suscitar. Decerto, ninguém recusaria que a atualidade, a urgência, a importância essencial a serem atribuídas a $O$ mestre ignorante se devem à centralidade que se concede à questão da igualdade. Aí, no entanto, começam já os problemas. E, de fato, temos dedicado à igualdade uma reverência sem igual: temos nos dado como tarefa defini-la, buscá-la, projetá-la, criticála: mas o que diabos dizer de, como propõe o texto, simplesmente verificála? Como então verificar o que justamente sempre nos esforçamos por denunciar como... uma ausência? "Quem estabelece a igualdade como objetivo a ser atingido, a partir da situação de desigualdade, de fato a posterga até o infinito. A igualdade jamais vem após, como resultado a ser atingido. Ela deve sempre ser colocada antes". (Idem, ibid., p. 11) 
Concedamos que, partindo da desigualdade, vimos, até aqui, nos dando como objetivo a sua superação. E que, apesar de nossas reiteradas proclamações de fé, o veredicto de postergação bem se aplica aos resultados a que chegamos. Mas como colocar a igualdade antes, ou seja, como pressuposto? Eis o que parece, definitivamente, uma impossibilidade, se não um escândalo, e a lista extenuante de objeçôes que podem ser levantadas contra essa simples formulação já serviria para nos desanimar. Rancière tem razão em alertar: para além de seu fundamento educacional evidente, a questão é propriamente filosófica e, antes de tudo, eminentemente política - a menos que, em seu fundamento filosófico por excelência, ela seja propriamente política e, por isso mesmo, desde a modernidade, eminentemente educacional.

Pois a conversão do político ao educacional é obra da modernidade, que, decretando ser impossível partir da igualdade política, estabeleceu que tudo estava a depender da educação do povo. Desde então, a educação pública, ao invés de decorrência, aparece como precondição para a participação política ampliada. No entanto, tornada questão educacional, a desigualdade política evidentemente não só não desaparece, mas se desdobra em uma nova desigualdade insobrepujável, a partir daí longamente realçada pelos esforços educativos que deveriam atenuá-la: aquela que divide a sociedade entre os que estão em condiçôes de exercer sua autonomia e aqueles que, para tanto, devem ainda ser educados.

Eis porque a inédita valorização, nos tempos modernos, da educação pública - e, com ela, grande número das significações desde então instituídas para o ato de ensinar - não pode ser dissociada do percurso totalmente excêntrico que, pelo instrumento da inflexão educacional, veio em toda parte descrevendo aquela que deve considerada a exigência essencial da democracia: a reivindicação da igualdade política dos cidadãos.

Muito antes das leituras críticas da década de 1970, relata-nos Rancière, Jacotot atacou-se à questão da dupla desigualdade; porém, ao fazê-lo com as próprias armas da prática educacional, ele colocou duplamente em cheque a lógica daquela que denominou a "sociedade pedagogizada". No espectro mais amplamente político, o princípio da igualdade fere a escrupulosa mistificação dos especialistas que parece atravessar os governos de esquerda e de direita como dogma inabalável do poder; mas, invocado para repensar a ordem educacional, é em nosso cotidiano que o escândalo se instala, desfigurando a lógica simplista de um "nós" sempre bem-intencionado e impoderoso, contra estas figuras impessoais e 
longínquas de poder que atendem por "eles" - com os quais nada teríamos em comum. A contigüidade entre o político e o educacional nos obriga a interrogar de que forma, em nossos modos de ser aluno e de ser professor, fornecemos sobrevida e valor ao mito da desigualdade que deveríamos extinguir.

Em outras palavras, é sob as bases da desigualdade que nossas experiências educacionais vêm sendo construídas e, com elas, nossos ideais, nossas expectativas, nossas concepçōes acerca do ensinar, do aprender, do mestre, do aluno, do saber... Ou será que não?

Não seria o movimento da Escola Nova a negação do postulado iluminista do saber demiúrgico - em favor, exatamente, da ênfase na exploração pessoal e da descoberta? Não há dúvidas de que o escolanovismo influenciou mais de uma geração de professores, introduzindo a vitoriosa, mas breve carreira do aprender a aprender sobre o ensino tradicional. No entanto, por maior que seja a tentação de ver no individualismo exacerbado a marca comum entre as duas posiçóes e de confundir o aluno-modelo dos métodos ativos com a atividade modelar dos alunos de Jacotot, é impossível negar que essa aproximação reduziria o cerne da proposta a uma questão de método, deixando escapar o fundo iluminista em que o experimentalismo pedagógico floresceu. A substituição da pedagogia tradicional da transmissão neutra do saber pela pedagogia renovada de exploração do saber deixa inteiramente intacto o mito da ciência moderna, de sua razoabilidade universal e, sobretudo, da legitimidade das hierarquias que estabelece, para os quais apenas fornece uma nova versão aprimorada, no seio da mesma sociedade pedagogizada em que os "melhores da turma" se transformam nos especialistas em poder.

Bem sabemos que, mais tarde, nos anos sessenta, a educação brasileira se propôs a descobrir a igualdade das culturas, ou a igualdade dos saberes. Desde então, a injunção metodológica de "partir da realidade do aluno" transformou-se em verdadeira profissão de fé, desmesurada e inquestionável, como todas as proclamaçôes do gênero. A fórmula não deixa de comportar, no entanto, seus graus de mistificação: entendida como princípio político de valoração epistemológica, ela dá origem a um voluntarismo que jamais chega a fazer suas provas de realidade; como preceito de atuação sócio-pedagógica, ela enclausura a identidade coletiva na simples reiteração; como estratégia didática, ajuda a promover a crença numa antropologia da incapacidade do outro se deixar motivar pela diferença. Porém, mais do que tudo, a própria idéia de "partir da realidade do aluno" comporta uma falácia lógica evidente, 
somente sustentada pela suposição de um mestre que conhece antecipadamente e melhor do que o próprio aluno qual é sua realidade.

Ora, a proposta de Jacotot não é um programa de valorização da cultura popular, e também não é a igualdade de saberes que ele anuncia; mais ainda, dissolvendo os nexos que, em nome do simples pragmatismo, da defesa de uma consciência de classe, ou de uma identidade cultural específica previamente se constroem entre origem social e vocação para o saber, ele propõe a educação como uma aventura sempre pessoal em direção à descoberta de seu próprio poder de autodeterminação. Mas, em se tratando, a rigor, de emancipação intelectual, como poderia ser diferente? Como poderia haver um roteiro preestabelecido?

Oferecendo uma retratação aos contra-sensos a que se expôs, teórica e praticamente, a noção de autonomia na modernidade, Jacotot/ Rancière expõe um dos pontos cegos de todo o pensamento herdado: a necessidade de dar um conteúdo à liberdade, de estabelecer um destino para a emancipação, de predizer as conseqüências da autonomia. É sem dúvida isso que concede à proposta de $O$ mestre ignorante essa espécie de coerência exacerbada, mas também o aparente desatino: a recusa de que, da experiência da igualdade das inteligências, se possa deduzir necessariamente uma sociedade igualitária. Mas é a afirmação contrária - pela qual de lá se deve que concluir que toda atividade política só pode resultar em desigualdade - que turva essa radicalidade, fazendo o discurso sucumbir às mesmas armadilhas que havia podido evitar.

A ordem social, em tudo quanto a compõe e a mantém, é arbitrária: a lição nada tem de novo, tanto quanto não é novidade que, para se manter, toda ordem social empreendeu o ocultamento dessa arbitrariedade, fabricando para si um fundamento natural, ou mesmo "racional". E o que é a sociedade, senão os indivíduos que a encarnam, as práticas e as instituiçôes que a mantêm? Particularmente para os que militam a causa da educação pública, a força da reflexão que nos oferece Rancière é que, por uma vez, essa discussão não está situada nas alturas de um poder impessoal e distante, contra o qual podemos dirigir nossas críticas consoladoras, mas totalmente ineficazes. Pedra de tropeço, a injunção à igualdade, na escola, nos devolve às nossas práticas e instituições, a nossos modos de ser professor e de alimentar a ficção desigualitária.

Pois partir da igualdade significa, para o professor, por uma vez, partir... de si mesmo. Reconhecer em si a igualdade: “(...) para emancipar a outrem, é preciso que se tenha emancipado a si próprio. É preciso conhecer-se a si mesmo como viajante do espírito, semelhante a todos os outros viajantes, como sujeito intelectual que participa da 
potência comum dos seres intelectuais." (idem, ibid., p. 57). Mas isso implica, de imediato, a renúncia a pelo menos dois grandes confortos. O primeiro é aquele que leva o professor a imaginar que sua posição se funda no saber que possui, ou pode vir a possuir - ainda, e sobretudo, esse vertiginoso "saber de nada saber" - pelo qual abdica de verificar sua própria inteligência, desiste de aventurar-se na descoberta de si, nessa pesquisa em que jamais "se encontra necessariamente aquilo que se buscava, menos ainda aquilo que é preciso encontrar, mas sempre uma coisa nova, a relacionar à coisa que já se conhece." (id., ibid.). Nesse percurso, não há qualquer tipo de garantias, ou de seguranças, mas, pelo contrário, a certeza de que ninguém se emancipa de uma vez por todas: é sempre possível e tentador abandonar a busca, fiar-se no saber "já conquistado", esperar as certezas que provêm do saber de outrem. Não são poucos, ademais, os apelos para que o professor desenvolva a arrogância corporativa que lhe permite, de alguma forma, assumir pública ou intimamente sua superioridade sobre os alunos e sobre os próprios colegas.

Tampouco se trata de fingir não saber, de teimar em igualar seu saber ao do aluno, furtar-se à pesquisa em nome da pesquisa do aluno. Não é essa, parece-me, a lição do mestre ignorante. Mas, ao contrário, a de que o professor adquira essa ousadia de se crer capaz do que os grandes pensadores foram capazes; e, ao mesmo tempo, que ele se sinta obrigado a, tal como solicitará do aluno, "ver tudo por ele mesmo, comparar incessantemente e sempre responder à tríplice questão: o que vês? O que pensas disso? O que fazes com isso? E assim, até o infinito." (idem, ibid., p. 44).

O segundo conforto a ser abandonado é aquele que leva o professor a imaginar que sua posição se funda no saber que o aluno não possui. Como não é seu saber - tanto, aliás, quanto não é sua ignorância - que o mestre comunica a seu aluno, até mesmo a ilusão de ser o guia, qualquer certeza de poder "emancipar seu aluno" mostra-se vã. Não há como dominar a vontade do aluno, a experiência da igualdade supõe uma adesão livre e incoercível. $\mathrm{O}$ mestre anuncia a igualdade, mas só o aluno pode verificá-la, fazendo-a existir para si. Nesse caminho, não mais do que a ignorância ("eu não posso"), o saber é obstáculo também para o aluno. $\mathrm{O}$ poder de uma inteligência se exerce sobre si própria: eis uma forma paradoxal de dizer que não há bons mestres, nem bons alunos, mas apenas professores e alunos que buscam incessantemente se emancipar.

Chegaríamos assim a uma sociedade de emancipados? A observação da política, tal como veio sendo praticada ao longo da história, conduz 
Jacotot a considerar que "não há sociedade possível... somente a sociedade que existe.” (idem, ibid., p. 109). Mas não testemunhou ele o que, pelo breve tempo revolucionário, se pôde operar, quando a política se fez atividade instituinte e questionadora? Essa outra via, que já não era a da "desrazão governante", mas a da liberdade, fundava-se na confiança na capacidade intelectual de cada ser humano (idem, ibid., p. 32): "Somente os preguiçosos tremeriam frente à idéia desse arbitrário, vendoo como o túmulo da razão. Ao contrário, é porque não há código dado pela divindade, língua da língua, que a inteligência humana emprega toda a sua arte em se fazer entender e em entender o que a inteligência vizinha lhe significa." (idem, ibid., p. 93).

Inversamente, o homem que aceita a ordem social "como um mistério situado para além do poder da razão" e que assim se submete "ao que a desrazão dos governantes exige" - ainda que evite "adotar as razões que ela proclama” (idem, ibid., p. 131), não estaria ainda preso a um círculo de desigualdade que condena os esforços de sua inteligência à inefetividade social? Em nome do que buscaria ele se emancipar?

Enfim, o próprio texto de Rancière nos mostra o quão longe se pode ir, quando o questionamento se instala. Refazendo o percurso de Joseph Jacotot em busca da inteligência, ele a observa como se ali tudo estivesse contido. O resultado é que é impossível lê-lo sem se contagiar por esta vontade de se lançar, também, na aventura de pensar, de significar, ou de ressignificar coisas para as quais há muito estamos desatentos, de cuja existência nem mais nos damos contas, coisas que parecem resolvidas de uma vez por todas na medida em que as exilamos para o território das coisas que não existem para nós.

Recebido e aprovado em fevereiro de 2003.

Referência bibliográfica

RANCIÈRE, J. O mestre ignorante. Cinco liçôes sobre a emancipação intelectual. Trad. Lílian do Valle. Belo Horizonte: Autêntica, 2002. (Série: Educação. Experiência e sentido). 